\title{
Sensitive, Accurate and Rapid Detection of the Northern Root-Knot Nematode, Meloidogyne hapla, Using Recombinase Polymerase Amplification Assays
}

\author{
Sergei A. Subbotin * and Julie Burbridge \\ Plant Pest Diagnostic Center, California Department of Food and Agriculture, 3294 Meadowview Road, \\ Sacramento, CA 95832, USA; burbridge.julie@gmail.com \\ * Correspondence: sergei.subbotin@cdfa.ca.gov
}

check for updates

Citation: Subbotin, S.A.; Burbridge, J. Sensitive, Accurate and Rapid Detection of the Northern Root-Knot Nematode, Meloidogyne hapla, Using Recombinase Polymerase

Amplification Assays. Plants 2021, 10, 336. https://doi.org/10.3390/ plants10020336

Academic Editor: Zafar Handoo

Received: 15 January 2021

Accepted: 8 February 2021

Published: 10 February 2021

Publisher's Note: MDPI stays neutral with regard to jurisdictional claims in published maps and institutional affiliations.

Copyright: (c) 2021 by the authors. Licensee MDPI, Basel, Switzerland. This article is an open access article distributed under the terms and conditions of the Creative Commons Attribution (CC BY) license (https:// creativecommons.org/licenses/by/ $4.0 /)$.

\begin{abstract}
Rapid and reliable diagnostics of root-knot nematodes are critical for selections of effective control against these agricultural pests. In this study, recombinase polymerase amplification (RPA) assays were developed targeting the IGS rRNA gene of the northern root-knot nematode, Meloidogyne hapla. The RPA assays using TwistAmp ${ }^{\circledR}$ Basic, TwistAmp ${ }^{\circledR}$ exo and TwistAmp ${ }^{\circledR}$ nfo kits (TwistDx, Cambridge, UK) allowed for the detection of $M$. hapla from crude extracts of females, eggs and juveniles without a DNA extraction step. The results of the RPA assays using real-time fluorescence detection (real-time RPA) in series of crude nematode extracts showed reliable detection after 13 min with a sensitivity of $1 / 100$ of a second-stage juvenile and up to $1 / 1000$ of a female in reaction tubes. The results of the RPA assays using lateral flow dipsticks (LF-RPA) showed reliable detection within 30 min with a sensitivity of $1 / 10$ of a second-stage juvenile and $1 / 1000$ of a female in reaction tubes. The RPA assay developed here is a successful tool for quick, accurate and sensitive diagnostics of M. hapla. The application of the LF-RPA assay has great potential for diagnosing infestation of this species in the lab, field or in areas with a minimal laboratory infrastructure.
\end{abstract}

Keywords: diagnostics; root-knot nematode; recombinase polymerase amplification

\section{Introduction}

The northern root-knot nematode, Meloidogyne hapla is one of the four most common root-knot nematode species worldwide. This nematode is extremely polyphagous, attacking a wide variety of crops and weeds. Meloidogyne hapla causes important economic losses for several horticultural, vegetable and pasture crops, including carrots, lettuce, lucerne, onion, potato, rose, sugarbeet, strawberry, white clover and others [1,2].

Accurate and rapid identification of nematodes is essential for their control. It has been shown that sequences of nuclear ribosomal genes: 18S rRNA, ITS rRNA, the D2-D3 of 28S rRNA, IGS rRNA and mitochondrial genes: COII-16S rRNA fragment, COI and COII clearly differentiate $M$. hapla from all other root-knot nematodes [3]. Several specific primers have been designed for the diagnostics of this species using conventional PCR [4-7]. Several authors also developed a TaqMan real-time PCR assay with species-specific primers for the detection of M. hapla from root galls and soil samples [8-12]. Recently, Peng et al. [13] developed loop-mediated isothermal amplification methods (LAMP) combined with a Flinders Technology Associates card for the identification of M. hapla.

Recombinase polymerase amplification (RPA), an isothermal in vitro nucleic acid amplification technique, has recently appeared as a novel molecular technology for simple, robust, rapid, reliable, and low-resource diagnostics. RPA represents a hugely versatile alternative to PCR [14-16]. RPA uses a highly efficient displacement polymerase that amplifies a few copies of target nucleic acid in $20 \mathrm{~min}$ at a constant temperature $\left(37-42{ }^{\circ} \mathrm{C}\right)$. It does so by utilizing three core enzymes: recombinase, single-stranded binding protein (SSB), and strand-displacing polymerase. The recombinase enzyme forms a complex with 
a primer to facilitate their binding to the targeted DNA template. Then, the SSB binds to the displaced strands of DNA and prevents the displacement of the recombinase-primer complex by branch migration. The strand-displacing polymerase then recognises the bound recombinase-primer complex and initiates DNA synthesis. Like PCR, RPA produces an amplicon constrained in size to the binding sites of the primers. The advantages of RPA include highly efficient and rapid amplification and a low constant operating temperature. RPA products can be detected by agarose gel electrophoresis or carried out by using fluorescent probes in real time (real-time RPA) or lateral flow strips (LF-RPA). RPA assays show high sensitivity and specificity for detecting various plant viruses, bacteria, fungi, vertebrate parasitic trematodes, nematodes and other organisms [17-22]. Real-time RPA detection assay of plant parasitic nematodes was first designed and published by Subbotin et al. [23] for Meloidogyne enterolobii. RPA assays were also developed for Meloidogyne javanica, M. arenaria and M. incognita [24,25] and Bursaphelenchus xylophilus [26,27]. Recently, Song et al. [28] described diagnostics of Meloidogyne hapla using RPA combined with a lateral flow dipstick assay, where species-specific primers and a probe were designed based on the effector gene 16D10 sequence. This LF-RPA assay allows detecting M. hapla from infested plant roots and soil samples and the entire detection process can be completed within $1.5 \mathrm{~h}$.

In our study, we developed real-time RPA and LF-RPA assays for the detection of Meloidogyne hapla using crude nematode and infected plant root extracts, with results within 13-30 min. Species-specific primers and probes were designed based on the IGS ribosomal RNA gene sequence.

\section{Results}

\subsection{RPA Primers and Probe Design}

All available sequences of the IGS rRNA for M. hapla and other Meloidogyne were downloaded from the Genbank and aligned with ClustalX. Several regions with high sequence dissimilarity between M. hapla and other Meloidogyne were assessed and several species-specific $M$. hapla candidate primers sets and probes were manually designed. The Blastn search of these species-specific candidate primer sequences and probe sequences showed high similarity $(100 \%)$ only with the IGS rRNA fragments of M. hapla deposited in the GenBank.

\subsection{RPA Detection}

Nine primer combination candidate sets were screened for the best performance under the same RPA conditions. The species-specific forward F3-IGS-Hapl and the species-specific reverse R3-IGS-Hapl primers were found to be optimal with clearly visible bands and had no cross-reactions with other root-knot nematodes (Table 1 ). The final sequences of primers and probes used for the assays are listed in Table 2 and are indicated in the IGS rRNA gene alignment in Figure 1. This primer set reliably and specifically amplified the target gene fragment, approximately $164 \mathrm{bp}$ in length from the IGS region (Figure 2) and was also confirmed by a direct sequencing of the product. Additional non-specific weak additional bands having other sizes were observed sometimes in experiments with $M$. hapla as well as samples with other root-knot nematode species (data not shown). 
Table 1. Samples of Meloidogyne hapla and other root-knot nematodes tested in the present study.

\begin{tabular}{|c|c|c|c|c|}
\hline Species & Location & Plant & Sample Code & Source \\
\hline M. hapla & USA, California & Tomato & VW9 & V. Williamson \\
\hline M. hapla & USA, California & Tomato & $\mathrm{C} 44$ & V. Williamson \\
\hline M. hapla & Moldova, Tiraspol & Sweet pepper & CD3384 & V. N. Chizhov \\
\hline M. hapla & USA, Balm, Florida & Strawberry & CD2461 & R.N. Inserra \\
\hline M. hapla & USA, Michigan, Van Buren County & Grapevine & CD3385e & S. Álvarez-Ortega \\
\hline M. arenaria & USA, Florida & Unknown & CD3093 & J.A. Brito \\
\hline M. arenaria & USA, Florida & Unknown & CD3100 & J.A. Brito \\
\hline M. baetica & Spain & Olive & CD3382 & P. Castillo \\
\hline M. christiei & USA Florida, & Turkey oak & CD1471 & J.A. Brito \\
\hline M. enterelobii & USA, UCR collection & Tomato & CD3386 & P. Roberts \\
\hline M. floridensis & USA, California, Kern county & Grapevine & CD3324 & S.A. Subbotin \\
\hline M. incognita & USA, Florida & Tomato & CD3038 & J.A. Brito \\
\hline M. javanica & USA, Florida & Tomato & CD3050 & J.A. Brito \\
\hline M. javanica & USA, UCR collection & Tomato & Isolate 40 & P. Roberts \\
\hline M. naasi & Germany & Grasses & CD3381 & D. Sturhan \\
\hline M. naasi & USA, California & Grasses & CD2158 & S.A. Subbotin \\
\hline M. nataliei & USA, Michigan, Van Buren County & Grapevine & CD3385a, b, c & S. Álvarez-Ortega \\
\hline Meloidogyne sp.1 & Germany & Grasses & CD3380 & D. Sturhan \\
\hline Meloidogyne sp.2 & Russia & Unknown & CD3383 & V. N. Chizhov \\
\hline
\end{tabular}

Table 2. RPA primers and probe for amplification of Meloidogyne hapla DNA.

\begin{tabular}{cc}
\hline Primer or Probe & Sequence $\left(\mathbf{5}^{\prime}-\mathbf{3}^{\prime} \mathbf{)}\right.$ \\
\hline F3-IGS-Hapl & TGC CAG TAC TCT GTT AGA AGT TGG TGA AGT GAT \\
R3-IGS-Hapl & GAA AAA TCC CCT CGA AAA ATC CAC CAT TTT AAT CCC T \\
R3-IGS-Hapl-biotin & [Biotin] GAA AAA TCC CCT CGA AAA ATC CAC CAT TTT AAT CCC T \\
Probe-hapla-exo1 & T GTC TTG TGC AAA GGA GAT TAT AAT TTG CTG GCT [FAM-dT] GT [THF] AT [BHQ1-dT] TTA \\
Probe-hapla-nfo1 & ATC TTT AAT CAT ATT[C3-spacer] * \\
& [FAM] T GTC TTG TGC AAA GGA GAT TAT AAT TTG CTG GCT TGT [THF] ATT TTA ATC TTT \\
& AAT CAT ATT[C3-spacer] *
\end{tabular}

*FAM-fluorophore, THF-tetrahydrofuran, BHQ—quencher, C3-spacer block.

\subsection{Real-Time RPA Detection Assays}

Using the results of nine experimental runs, which included positive and negative controls with water and non-target DNA, the threshold level for reliable $M$. hapla detection was established as equal to 8 cycles ( $\sim 3 \mathrm{~min}$ ) with a baseline of $250,000(\Delta \mathrm{Rn})$ fluorescence using the TwistAmp ${ }^{\circledR}$ exo kit on the Applied Biosystems ${ }^{\mathrm{TM}}$ QuantStudio $^{\mathrm{TM}} 7$ Flex Real-Time PCR System (Figures 3 and 4A). Samples that produced an exponential amplification curve above the threshold were considered as positive for M. hapla and below the threshold were considered as negative. Detection of M. hapla was confirmed with all samples. 


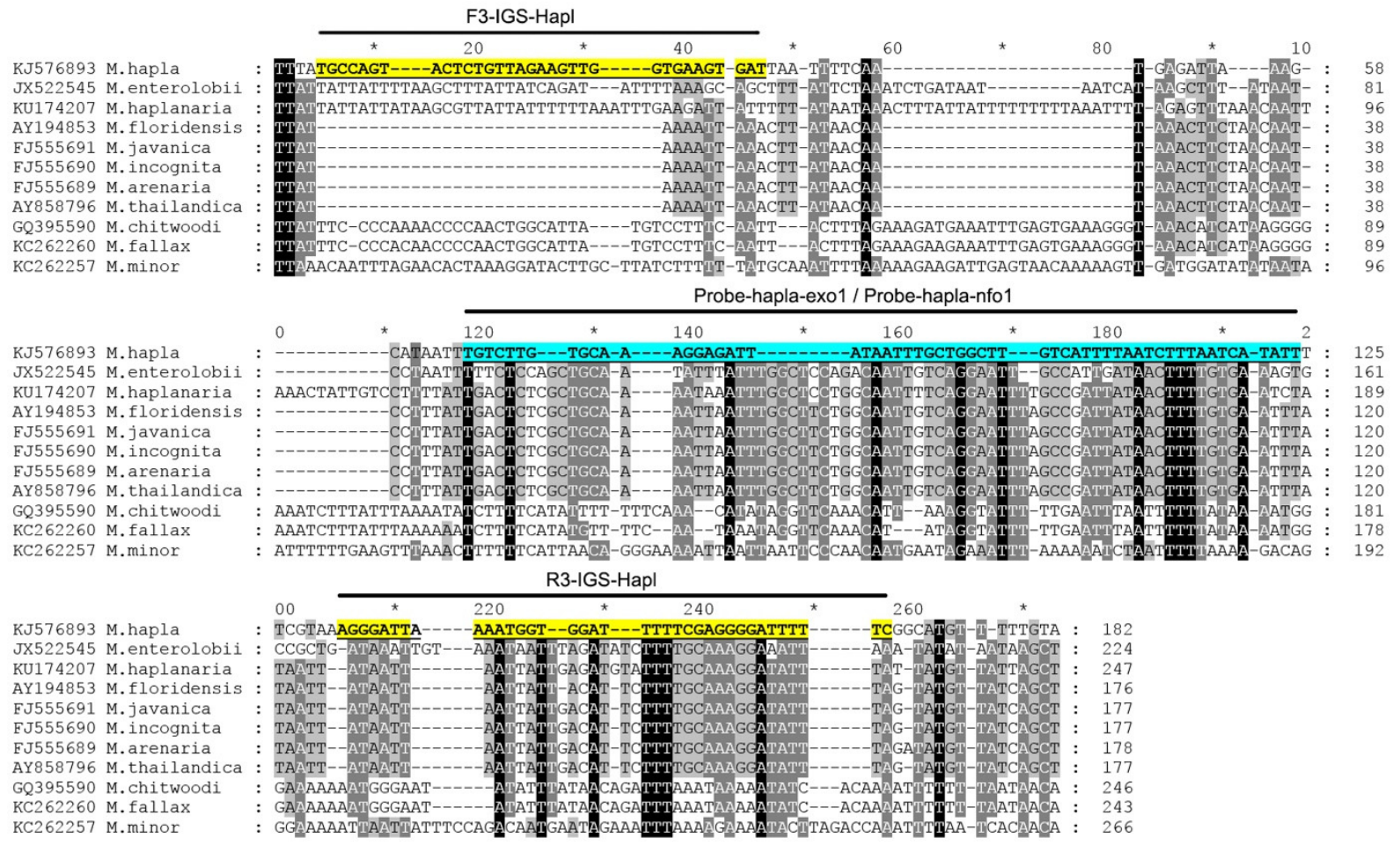

Figure 1. The fragment of alignment of the IGS rRNA gene sequences for several root-knot nematodes, Meloidogyne, with the positions of recombinase polymerase amplification (RPA) primers and probes used in the present study.

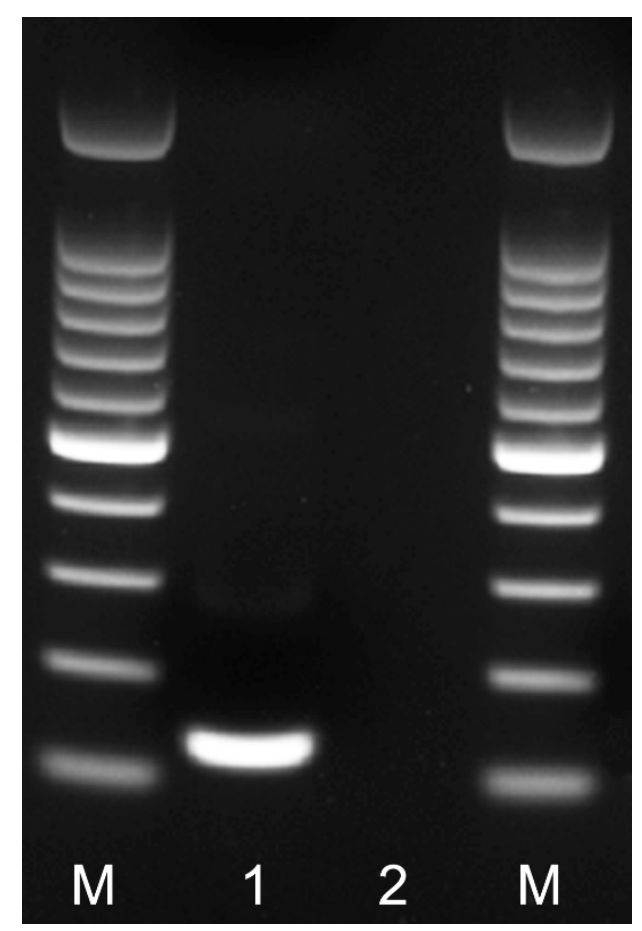

Figure 2. RPA amplicon of the partial IGS rRNA gene on agarose gel. Lanes: M: $100 \mathrm{bp}$ DNA marker (Promega, Madison, WI, USA); 1: RPA amplicon obtained after $24 \mathrm{~min}$ at $39^{\circ} \mathrm{C}$ with F3-IGS-Hapl and R3-IGS-Hapl primers using TwistAmp ${ }^{\circledR}$ Basic kit; 2: negative control. 

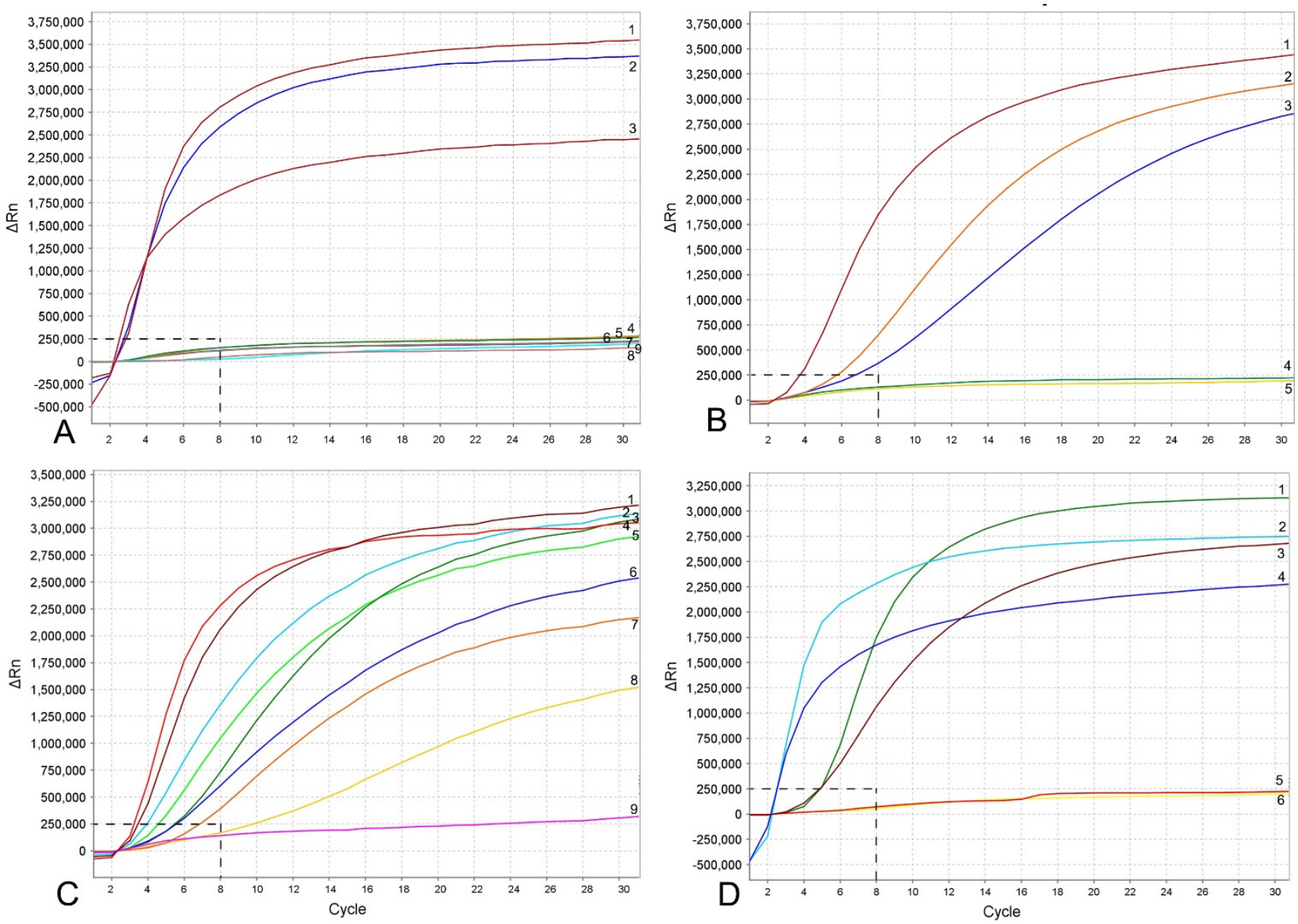

Figure 3. RPA assays using real-time fluorescent detection with examples of amplification plots. (A) Specificity assay with DNA samples of Meloidogyne spp. and crude second-stage juvenile (J2) extracts of M. hapla. Line: 1: M. hapla (CD2461); 2: M. hapla (VW9); 3: M. hapla (C44); 4: M. incognita (CD3038); 5: M. arenaria (CD3100); 6: Meloidogyne naasi (CD3381); 7: M. javanica (isolate 40); 8 and 9: negative control; (B) sensitivity assay with a dilution series of a crude J2 extract of M. hapla, line: 1: $1 \mathrm{~J} 2$ per tube; 2: 1/10 J2 per tube; 3: 1/100 J2 per tube; 4: 1/1000 J2 per tube; 5: negative control; (C) crude extract of $M$. hapla with or without crude extracts of non-target nematodes. Line: 1 and 4: $1 \mathrm{~J} 2$ per tube; 2, 5L $1 \mathrm{~J} 2$ with 20 non-target nematodes per tube; 3 and 6: $1 \mathrm{~J} 2$ with 10 non-target nematodes per tube; 7 and 8: $1 \mathrm{~J} 2$ per tube containing half of a reaction mixture; 9: negative control; (D) testing of crude extracts of $M$. hapla. Line: 1: $1 \mathrm{~J} 2$ per tube; 2 and 4: extracts from infected plant roots containing females with egg-masses; 3 and 6: extracts from infected plant roots containing old females without egg-masses; 5 : negative control. The vertical line on a graph: fluorescence $\Delta \mathrm{Rn}$. $\Delta \mathrm{Rn}$ is calculated at each cycle as DRn (cycle) = Rn (cycle)—Rn (baseline), where Rn = normalized reporter. The horizontal line on a graph: cycles, each cycle $=20 \mathrm{~s}$. 

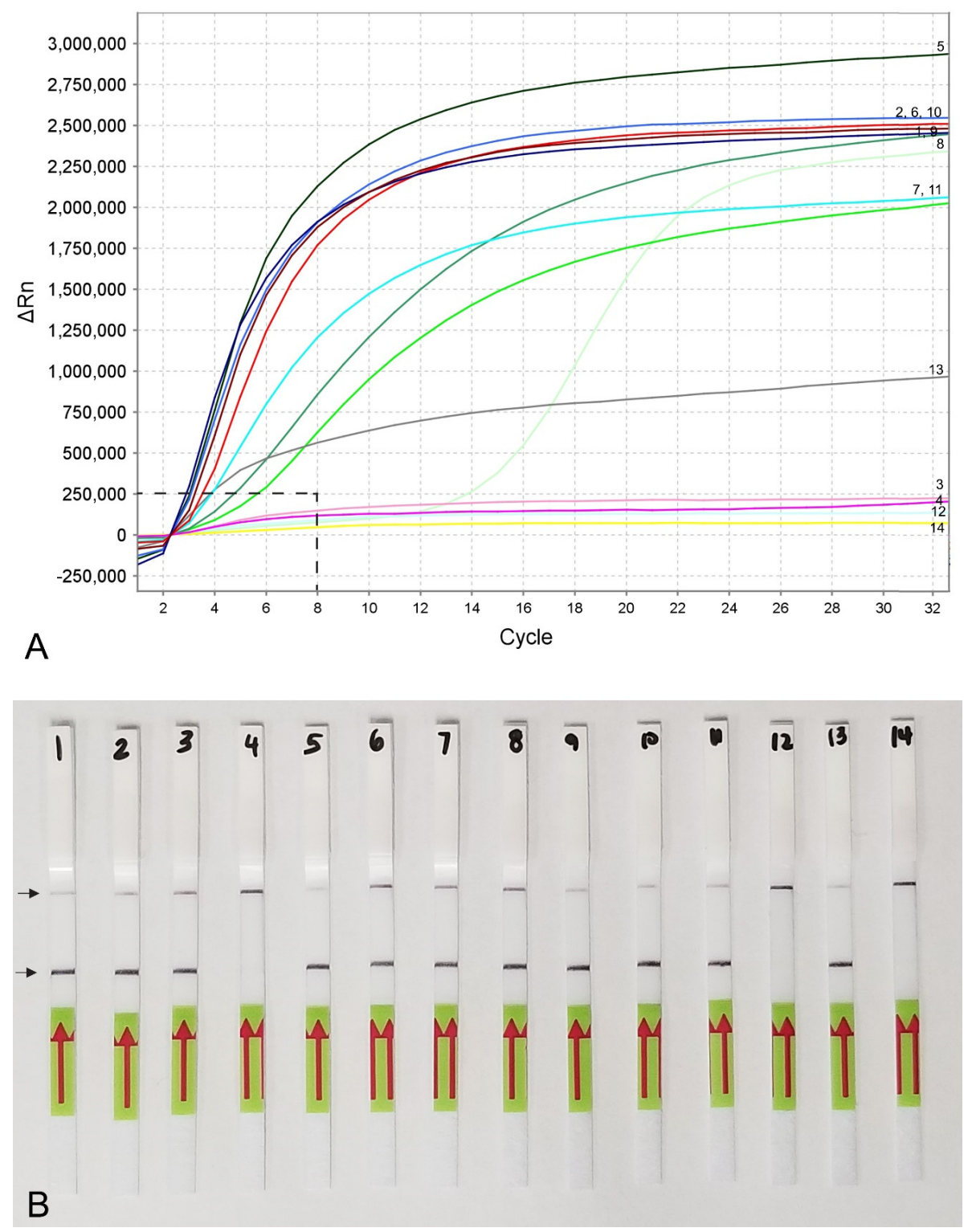

Figure 4. RPA sensitivity assays using (A) real-time fluorescent detection and (B) lateral flow strips. A dilution series of three crude young females (without egg-masses) extracts of M. hapla. Line (Strip): 1, 5, 9: 1/10 female per tube; 2, 6, 10: 1/100 female per tube; $3,7,11: 1 / 1000$ female per tube; $4,8,12: 1 / 10,000$ female per tube; 13 : positive control; 14: negative control. Control (upper) and test (lower) lines are indicated by arrows.

The RPA assay was tested for specificity using DNA extracted from several rootknot nematodes. These nematodes include: Meloidogyne arenaria, M. baetica, M. christiei, M. enterelobii, M. floridensis, M. incognita, $M$. javanica, M. naasi and M. nataliei. The RPA results using real-time fluorescent detection showed high specificity to $M$. hapla only and no cross-reactions were observed against other root-knot nematode species (Figure 3A).

The sensitivity assay was designed for evaluation of the detection limit. Variants with serial dilutions $(1,1 / 10,1 / 100,1 / 1000$ and $1 / 10,000$ per reaction tube) of crude nematode extractions were obtained from second-stage juveniles (J2s) or females without egg-masses. The reliable detection level of $M$. hapla was estimated at 1/100 of one J2 per a RPA reaction tube (Figure 3B). The detection level of $M$. hapla females varied among replicates and reached $1 / 100,1 / 1000$ and $1 / 10,000$ of a female for three, two and one replicates, respectively (Figure $4 \mathrm{~A}$ ).

The detection of $\mathrm{J} 2$ for $M$. hapla was confirmed in the presence of background crude extracts from at least 20 non-target nematodes. No decrease in fluorescent signals was 
observed between the variant of $1 \mathrm{~J} 2$ without other nematodes and the variants with $1 \mathrm{~J} 2$ with 10 and 20 non-target nematodes (Figure 3C). Lowering in half, a single reaction assay volume showed a decrease in fluorescence signal and reaction rate (Figure 3C). These samples could be considered as positive with threshold level of 12 cycles ( 6 $\mathrm{min}$ ).

Meloidogyne hapla detection was also confirmed using extracts obtained from infected tomato and pepper plant roots containing females with egg-masses. Although most replicates from extracts obtained from infected plant roots containing old females without egg-masses gave strong signals, one replicate showed no fluorescence signal (Figure 3D).

\subsection{LF-RPA Assay}

Lateral flow detection of RPA products also showed specific and sensitive results. Positive test lines on the LF strips were observed for all M. hapla samples, whereas samples with other nematode species showed only a control line (Figure 5A). The detection of J2 for M. hapla was confirmed from extracts of infected pepper roots with $M$. hapla (Figure 5B) as well as in the presence of background crude extract from 10 to 20 non-target nematodes (Figure 5C). Lowering in half, a single reaction assay volume still detected $M$. hapla samples (Figure 5C). The results of RPA assays showed reliable detection with a sensitivity of $1 / 10$ of a J2 (Figure 5D) and 1/1000 of a female (Figure 4B) in reaction tubes.

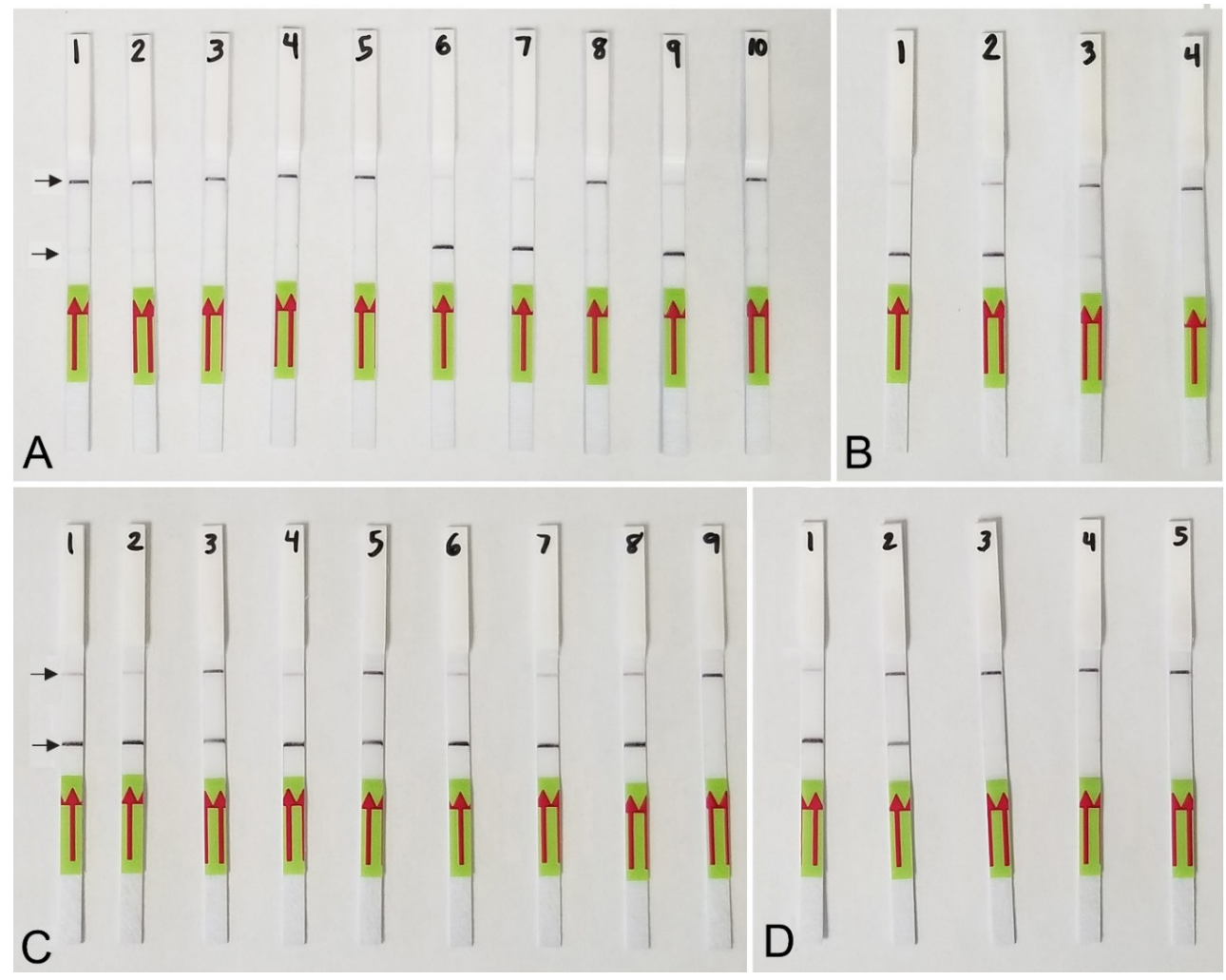

Figure 5. Lateral flow recombinase polymerase amplification (LF-RPA) assay with examples of lateral flow strips. (A) Specificity assay with DNA samples of Meloidogyne spp. and crude J2 extracts of M. hapla. Strip: 1 and 2: Meloidogyne sp.1 (CD3380); 3: M. naasi (CD3381); 4: M. baetica (CD3382); 5: Meloidogyne sp.2 (CD3383); 6 and 7: M. hapla, (CD3384); 8: M. arenaria (CD33093); 9: M. hapla (C44); 10: negative control; (B) crude extracts of M. hapla. Strip: 1 and 2: extracts from infected tomato roots containing plant materials and females with egg-masses; 3 : $1 \mathrm{j} 2$ per tube; 4 : negative control; (C) testing of crude extract of $M$. hapla with or without crude extracts of non-target nematodes. Strip: 1 and 2: $1 \mathrm{~J} 2$ per tube; 3 and 4: $1 \mathrm{~J} 2$ with 10 non-target nematodes per tube; 5 and 6: $1 \mathrm{~J} 2$ with 20 non-target nematodes per tube; 7 and 8: $1 \mathrm{~J} 2$ per tube containing half of a reaction mixture; 9 : negative control; (D) sensitivity assay with a dilution series of a crude $j 2$ extract of M. hapla, Strip: 1: $1 \mathrm{~J} 2$ per tube; 2: 1/10 J2 per tube; 3: 1/100 J2 per tube; 4: 1/1000 J2 per tube; 5: negative control (upper) and test (lower) lines are indicated by arrows. 


\section{Discussion}

Polymerase chain reaction is considered the gold standard of molecular detection, however, this method is only available in a laboratory with thermal cycling equipment. In this work, we have developed an affordable, simple, fast and sensitive real-time RPA and LF-RPA assays to detect $M$. hapla from nematode specimens extracted from plant and soil samples. An LF-RPA assay can be performed in a field condition without any special equipment or in areas with a minimal laboratory infrastructure.

Song et al. [28] described the LF-RPA diagnostic assay of M. hapla using species-specific primers and a probe designed using the effector gene 16D10 sequence. Authors stated that the entire detection process can be completed within $1.5 \mathrm{~h}$, including 30-60 $\mathrm{min}$ for DNA extraction, $20 \mathrm{~min}$ for the RPA reaction, and 3-5 min for visual detection on the LF strips [28]. In our assay, the species-specific primers and probes were designed using the IGS rRNA gene sequence. The entire detection process for the LF-RPA assay can be completed within approximately $30 \mathrm{~min}$, including $4 \mathrm{~min}$ for crude nematode extract preparation, $20 \mathrm{~min}(4+16)$ for the RPA reaction, 1 min for mixing and centrifugation of tubes, and $5 \mathrm{~min}$ for visual detection on the LF strips. The entire detection process for real-time RPA assay can be completed within approximately $13 \mathrm{~min}$, including $4 \mathrm{~min}$ for crude nematode extract preparation, $8 \mathrm{~min}(5+3)$ for the RPA reaction with $1 \mathrm{~min}$ for mixing and centrifugation of tubes. This calculation does not include the time for preparation of the RPA reaction mixture.

In our study the IGS rRNA gene was selected for the RPA assays because of its high copy number and because previously published PCR studies have demonstrated its usefulness to distinguish Meloidogyne species [7,29,30]. Zhang et al. [16] noticed that different DNA targets are likely to have extremely different amplification efficiencies, even sharing a series of common characteristics including GC content, primer melting temperature and RPA product length. These authors also concluded that primers are the most important determinant for RPA performance including sensitivity, specificity and reaction rate. Although amplicons obtained from fragments of effector gene $16 D 10$ and the IGS rRNA gene are comparable (148 vs. $164 \mathrm{bp}$ ) in a length, it seems that the RPA reaction rate is higher for the IGS rRNA gene than the effector gene fragment. The RPA assays developed based on the IGS rRNA gene are more sensitive for detection than assays based on the effector gene fragment.

Song et al. [28] reported about 1/1000 female (after DNA extraction with proteinase $\mathrm{K})$ as the detection limit of the LF-RPA assay, whereas in our LF-RPA assay, the detection limit can reach up to $1 / 10,000$ (without a special DNA extraction step). Our RPA assays for M. hapla also showed higher amplification rates compared with similar assays developed for M. enterolobii, in which species-specific primers were also designed based on the IGS rRNA gene [23]. The threshold level for the reliable M. enterolobii detection was established as equal to 30 cycles $(=10 \mathrm{~min})$ and a baseline of $500,000(\Delta \mathrm{Rn})$ fluorescence level with the TwistAmp ${ }^{\circledR}$ exo kit and Applied Biosystems ${ }^{\mathrm{TM}}$ QuantStudio $^{\mathrm{TM}}$ Flex Real-Time PCR System, whereas in our present study for M. hapla, the threshold level was estimated equal to 8 cycles ( $\sim 3 \mathrm{~min})$ and a baseline of 250,000 .

The real-time RPA and LF-RPA assays developed in our study allowed the detection of J2, young females without and with eggs-masses. The old and dead females without body contents might not be always detectable using this method. The results of our study estimated that the reliable detection of RPA assays using real-time fluorescence were 1/100 of $\mathrm{J} 2$ or female and using lateral flow dipsticks were $1 / 10$ of a J2 and 1/1000 of a female. However, in some replicates the detection limit can reach up to $1 / 10,000$ of a female in reaction tube. Reproducibility of the assays in low concentrations of nematode extracts, extracts from old females or directly from soil samples should be carefully tested further to understand factors, which might have an influence on the performing stability of RPA reactions. RPA diagnostics of root-knot nematodes has several other important advantages over PCR methods. The first advantage is that crude nematode extracts or crude extracts from nematode-infected tomato and pepper plant tissues can be directly used for RPA 
assays, whereas PCR assays require a DNA extraction step with special treatment of these extracts before use. The second advantage of RPA assays is that results are available in 8-20 min, whereas the results of PCR assays can be observed in 1.5-3 h. The third advantage is higher sensitivity levels of RPA detection over PCR methods; the RPA assay is 10 or 100 times more sensitive than PCR.

However, the application of RPA assays for nematode diagnostics may still face several problems, with cost being a major consideration. Factors affecting the expense of assays depends on the pest, reagent costs, requirement for equipment, infrastructure capacity, employee wages and numbers of samples for testing, among others. The RPA reagents and kits are presently manufactured by only one company, TwistDx, Inc., making the cost of the RPA assay relatively higher than other PCR assays. Reagent costs for RPA assays are currently in range of USD 4.3-5.5 per sample [15] which is higher than for conventional and real-time PCR. Lillis et al. [31] showed that lowering the assay volume from $50 \mu \mathrm{L}$, which is the recommended in the manufacturer's protocol, to $5 \mu \mathrm{L}$ showed similar sensitivity. Our experiments also revealed acceptable diagnostic performance when reducing the reaction volume by half. This approach could be used in cases of resource limitations. It has been noticed that special attention should be paid to the potential of cross-contamination due to the high sensitivity of this reaction. The requirement for use of clean gloves, tubes, and pipets should be carefully considered during the use of RPA assays in a field condition. Thus, RPA has the potential to be a promising alternative to PCR and other methods for rapid detection of nematodes. This assay requires minimal sample preparation, making it ideal for use in the lab, the field, or minimal laboratory infrastructure.

\section{Materials and Methods}

\subsection{Nematode Samples}

Five isolates of Meloidogyne hapla were obtained for RPA assay development. Secondstage juveniles (J2s) and females were extracted from the root or soil samples. The D2-D3 expansion segments of the $28 \mathrm{~S}$ rRNA gene were sequenced from each isolate to confirm its identity. DNA of several root-knot nematodes, M. arenaria, M. baetica, M. christiei, M. enterelobii, M. floridensis, M. incognita, M. javanica, M. naasi and $M$. nataliei were also used in specificity experiments (Table 1). These species were also identified by molecular methods. Free-living and plant parasitic nematodes from several field samples collected in California were extracted using the centrifugal flotation method and their extracts were used as background non-target DNA.

\subsection{Nematode Extracts}

Second-stage juveniles or females of $M$. hapla were placed in distilled water on a microscope slide. The nematodes were cut using a dental needle under a stereo microscope and put into a $0.2 \mathrm{~mL}$ PCR tube with a total volume of $10 \mu \mathrm{L}$. This stock crude extract was used to make a series of dilutions sequentially: 1:2, 1:4, 1:8, 1:10, 1:16, 1:100, 1:1000 and 1:10,000 in water. Several extracts were prepared: (i) J2s; (ii) J2s with other non-target nematodes; (iii) female and (iv) plant gall tissue with one or more females and egg-masses. Crude extract of plant gall tissue with nematodes and crude extract of several hundred non-target nematodes soil free-living and plant parasitic nematodes were also obtained by crushing the samples on a microscope slide using a plastic pipe tip or dental needle.

\subsection{RPA Primer Design and Testing}

A total of three forward and three reverse RPA primers specific to M. hapla were manually designed based on species sequence polymorphisms in the IGS rRNA gene. Primers were synthesized by Integrated DNA Technologies, Inc. (Redwood City, CA, USA). Nine primer sets were screened in different combinations using the TwistAmp ${ }^{\circledR}$ Basic kit (TwistDx, Cambridge, UK). Reactions were prepared according to the manufacturer's instructions. The lyophilized reaction pellets were suspended in $29.5 \mu \mathrm{L}$ of the rehydration buffer, $2.4 \mu \mathrm{L}$ of each forward and reverse primers $(10 \mu \mathrm{M})$ (Table 2$), 1 \mu \mathrm{L}$ of 
the DNA template or nematode extract and $12.2 \mu \mathrm{L}$ of distilled water. For each sample, $2.5 \mu \mathrm{L}$ of $280 \mathrm{mM}$ magnesium acetate was added to the lid of the tube and the lids were closed carefully. The tubes were inverted 10-15 times and briefly centrifuged to initiate reactions simultaneously. Tubes were incubated at $39^{\circ} \mathrm{C}(4 \mathrm{~min})$ in a MyBlock Mini Dry Bath (Benchmark Scientific, Edison, NJ, USA) and then they were inverted 10-15 times, briefly centrifuged and returned to the incubator block $\left(39^{\circ} \mathrm{C}\right)$ for $20 \mathrm{~min}$. Sample tubes were then placed in a freezer to stop the reaction. Amplification products were purified with a QIAquick PCR Purification Kit (Qiagen, Valencia, CA, USA). Five $\mu \mathrm{L}$ of purified product were run in a 1\% TAE (Tris-acetate-EDTA)-buffered agarose gel (100 V, $60 \mathrm{~min})$ and visualized with Gel Green stain. Amplification products were directly sequenced by Genewiz (San Francisco, CA, USA) using amplification primers.

\subsection{Real-Time RPA Assay}

Two TwistAmp ${ }^{\circledR}$ exo probes were designed according to the manufacturer's instructions and were synthesized by Biosearch Technologies, Inc. (Petaluma, CA, USA). Two probes were tested and only one probe (Probe-hapla-exo1) was selected for the assay (Table 2) based on best amplification performance. The real time detection of RPA assay products was accomplished using the TwistAmp ${ }^{\circledR}$ exo kit (TwistDx, Cambridge, UK). The lyophilized reaction pellets were suspended in $29.5 \mu \mathrm{L}$ of the rehydration buffer, $2.1 \mu \mathrm{L}$ of each forward and reverse primers $(10 \mu \mathrm{M})$ (Table 2), $0.6 \mu \mathrm{L}$ of the probe $(10 \mu \mathrm{M}), 1 \mu \mathrm{L}$ of the DNA template or nematode extract and $12.2 \mu \mathrm{L}$ of distilled water. Magnesium acetate in a volume of $2.5 \mu \mathrm{L}$ was added to the lid of each tube, the lids were carefully closed, tubes were inverted 10-15 times and briefly centrifuged. The reaction tubes were incubated at $39^{\circ} \mathrm{C}$ for $5 \mathrm{~min}$, then inverted $10-15$ times to mix, and briefly centrifuged. The tubes were immediately placed in Applied Biosystems ${ }^{\mathrm{TM}}$ QuantStudio $^{\mathrm{TM}} 7$ Flex Real-Time PCR System to incubate at $39^{\circ} \mathrm{C}$ for $15 \mathrm{~min}$. The fluorescence signal was monitored in real time and measured every $20 \mathrm{~s}$ (cycle) using the fluorophore (FAM) channel. A positive control using M. hapla extract (one J2 per reaction tube) and negative control without any nematode DNA were included in each run. Two or three replicates of each variant across several runs were performed for sensitivity and specificity experiments.

\subsection{LF-RPA Assay}

Two TwistAmp ${ }^{\circledR}$ nfo probes were designed according to the manufacturer's instructions and tested in the same conditions. Only one probe (Probe-hapla-nfo1) was selected for the assay based on the best visualization results. The LF-RPA assay products were accomplished using the TwistAmp ${ }^{\circledR}$ nfo kit (TwistDx, Cambridge, UK). The reaction mixture for each RPA assay was prepared according to the manufacturer's instructions: the lyophilized reaction pellets were suspended in $29.5 \mu \mathrm{L}$ of the rehydration buffer, $2.1 \mu \mathrm{L}$ of each forward and reverse primers $(10 \mu \mathrm{M}), 0.6 \mu \mathrm{L}$ of the probe $(10 \mu \mathrm{M}), 1 \mu \mathrm{L}$ of the DNA template or nematode extract and $12.2 \mu \mathrm{L}$ of distilled water. Magnesium acetate in a volume of $2.5 \mu \mathrm{L}$ was added to the lid of each tube, the lids were carefully closed, and the tubes were inverted 10-15 times and briefly centrifuged. The reaction tubes were incubated at $39^{\circ} \mathrm{C}$ for $4 \mathrm{~min}$, then inverted $10-15$ times to mix, briefly centrifuged and returned to the incubator block at $39^{\circ} \mathrm{C}$ for $16 \mathrm{~min}$. The tubes were placed in the freezer to stop the reaction. For visual analysis with Milenia ${ }^{\circledR}$ Genline Hybridetect-1 strips (Milenia Biotec $\mathrm{GmbH}$, Giessen, Germany), testing solution containing $48 \mu \mathrm{L}$ of HybriDetect assay buffer and $12 \mu \mathrm{L}$ of the sample RPA product was prepared in a $0.5 \mathrm{~mL}$ PCR tube. Ten $\mu \mathrm{L}$ of the testing solution was placed directly onto the sample area of the dipstick. Dipsticks were placed upright into $100 \mu \mathrm{L}$ of the assay buffer and visual results were observed within $5 \mathrm{~min}$. The amplification product was indicated by the development of a colored test line, and/or a separate control line to confirm that the system worked properly (Figures 4B and 5). Two or three replicates of each variant were performed for sensitivity and specificity experiments. 
Author Contributions: Conceptualization, S.A.S.; methodology, S.A.S.; software, J.B. and S.A.S.; validation, J.B. and S.A.S.; formal Analysis, J.B. and S.A.S.; investigation, J.B. and S.A.S.; resources, J.B. and S.A.S.; data Curation, J.B. and S.A.S.; writing-original draft preparation, S.A.S.; writing-review and editing, J.B. and S.A.S.; visualization, J.B. and S.A.S.; supervision, S.A.S.; project administration, S.A.S.; funding acquisition, S.A.S. All authors have read and agreed to the published version of the manuscript.

Funding: This work was sponsored by the Specialty Crop Block Grant Program (USDA Project Number: AM190100XXXXG008; CDFA Grant Number: 19-0001-035-MU).

Institutional Review Board Statement: Not applicable.

Informed Consent Statement: Not applicable.

Data Availability Statement: The datasets generated during and/or analyzed during the currentstudy are available from the corresponding author on reasonable request.

Acknowledgments: The authors thank Álvarez-Ortega, S., Brito, J., Chizhov, V.N., Castillo, P., Inserra, R.N., Roberts, P. and Williamson V. for providing the root-knot nematode samples.

Conflicts of Interest: The authors declare no conflict of interest.

\section{References}

1. Koenning, S.; Overstreet, C.; Noling, J.; Donald, P.; Becker, J.; Fortnum, B. Survey of crop losses in response to phytoparasitic nematodes in the United States for 1994. J. Nematol. 1999, 31, 587-618. [PubMed]

2. Perry, R.N.; Moens, M.; Starr, J.L. Meloidogyne species-A diverse group of novel and important plant parasites. In Root-Knot Nematodes; Perry, R.N., Moens, M., Starr, J.L., Eds.; CAB International: Wallingford, UK, 2009; pp. 1-17.

3. Alvarez-Ortega, S.; Brito, J.A.; Subbotin, S.A. Multigene phylogeny of root-knot nematodes and molecular characterization of Meloidogyne nataliei Golden, Rose \& Bird, 1981 (Nematoda: Tylenchida). Sci. Rep. 2019, 9, 11788. [PubMed]

4. Williamson, V.M.; Caswell-Chen, E.P.; Westerdahl, B.B.; Wu, F.F.; Caryl, G. A PCR assay to identify and distinguish single juveniles of Meloidogyne hapla and M. chitwoodi. J. Nematol. 1997, 29, 9-15.

5. Zijlstra, C. Identification of Meloidogyne chitwoodi, M. fallax and M. hapla based on SCAR-PCR: A powerful way enabling reliable PCR-based techniques for Meloidogyne identification of populations or individuals that share common traits. Eur. J. Plant Pathol. 2000, 106, 283-290. [CrossRef]

6. Dong, K.; Dean, R.A.; Fortnum, B.A.; Lewis, S.A. Development of PCR primers to identify species of root-knot nematodes: Meloidogyne arenaria, M. hapla, M. incognita and M. javanica. Nematropica 2001, 31, 271-280.

7. Wishart, J.; Phillips, M.S.; Blok, V.C. Ribosomal intergenic spacer: A Polymerase Chain Reaction diagnostic for Meloidogyne chitwoodi, M. fallax, and M. hapla. Phytopathology 2002, 92, 884-892. [CrossRef] [PubMed]

8. Dong, L.L.; Yao, H.; Li, Q.S.; Song, J.Y.; Li, Y.; Luo, H.M.; Chen, S.L. Investigation and integrated molecular diagnosis of root-knot nematodes in Panax notoginseng root in the field. Eur. J. Plant Pathol. 2013, 137, 667-675. [CrossRef]

9. Watanabe, T.; Masumura, H.; Kioka, Y.; Noguchi, K.; Min, Y.Y.; Murakami, R.; Toyota, K. Development of a direct quantitative detection method for Meloidogyne incognita and M. hapla in andosol and analysis of relationship between the initial population of Meloidogyne spp. and yield of eggplant in an andosol. Nematol. Res. 2013, 43, 21-29. [CrossRef]

10. Hay, F.S.; Herdina Ophel-Keller, K.; Hartley, D.M.; Pethybridge, S.J. Prediction of potato tuber damage by root-knot nematodes using quantitative DNA assay of soil. Plant Dis. 2016, 100, 592-600. [CrossRef]

11. Sapkota, R.; Skantar, A.M.; Nicolaisen, M. A TaqMan real-time PCR assay for detection of Meloidogyne hapla in root galls and in soil. Nematology 2016, 18, 147-154. [CrossRef]

12. Gorny, A.M.; Wang, X.H.; Hay, F.S.; Pethybridge, S.J. Development of a species-specific PCR for qetection and quantification of Meloidogyne hapla in soil using the 16D10 root-knot nematode effector gene. Plant Dis. 2019, 103, 1902-1909. [CrossRef]

13. Peng, H.; Long, H.; Huang, W.; Liu, J.; Cui, J.; Kong, L.; Hu, X.; Gu, J.; Peng, D. Rapid, simple and direct detection of Meloidogyne hapla from infected root galls using loop-mediated isothermal amplification combined with FTA technology. Sci. Rep. 2017, 7, 44853. [CrossRef]

14. Piepenburg, O.; Williams, C.H.; Stemple, D.L.; Armes, N.A. DNA detection using recombination proteins. PLoS Biol. 2006, 4, e204. [CrossRef]

15. Daher, R.K.; Stewart, G.; Boissinot, M.; Bergeron, M.G. Recombinase polymerase amp lification for diagnostic applications. Clin. Chem. 2016, 62, 947-958. [CrossRef]

16. Zhang, Y.; Hu, J.Q.; Li, Q.M.; Guo, J.Q.; Zhang, G.P. Chapter 10-Detection of microorganisms using recombinase polymerase amplification with lateral flow dipsticks. Methods Microbiol. 2020, 47, 319-349. [CrossRef]

17. Miles, T.D.; Martin, F.N.; Coffey, M.D. Development of rapid isothermal amplification assays for detection of Phytophthora spp. in plant tissue. Phytopathology 2015, 105, 265-278. [CrossRef]

18. Lau, H.Y.; Wang, Y.L.; Wee, E.J.H.; Botella, J.R.; Trau, M. Field demonstration of a multiplexed point-of-care diagnostic platform for plant pathogens. Anal. Chem. 2016, 88, 8074-8081. [CrossRef] 
19. Londoño, M.A.; Harmon, C.L.; Polston, J.E. Evaluation of recombinase polymerase amplification for detection of begomoviruses by plant diagnostic clinics. Virol. J. 2016, 13, 48. [CrossRef]

20. Cabada, M.M.; Malaga, J.L.; Castellanos-Gonzalez, A.; Bagwell, K.A.; Naeger, P.A.; Rogers, H.K.; Maharsi, S.; Mbaka, M.; White, A.C., Jr. Recombinase Polymerase Amplification compared to real-time Polymerase Chain Reaction test for the detection of Fasciola hepatica in human stool. Am. J. Trop. Med. Hyg. 2017, 96, 341-346. [CrossRef]

21. Li, T.-T.; Wang, J.-L.; Zhang, N.-Z.; Li, W.-H.; Yan, H.-B.; Li, L.; Jia, W.-Z.; Fu, B.-Q. Rapid and visual detection of Trichinella spp. using a lateral flow strip-based Recombinase Polymerase Amplification (LF-RPA) assay. Front. Cell. Infect. Microbiol. $2019,9,1$. [CrossRef]

22. Jarvi, A.I.; Atkinson, E.S.; Kaluna, L.M.; Snook, K.A.; Steel, A. Development of a recombinase polymerase amplification (RPAEXO) and lateral flow assay (RPA-LFA) based on the ITS1 gene for the detection of Angiostrongylus cantonensis in gastropod intermediate hosts. Parasitology 2020, 4, 1-8. [CrossRef] [PubMed]

23. Subbotin, S.A. Recombinase polymerase amplification assay for rapid detection of the root-knot nematode Meloidogyne enterolobii. Nematology 2019, 21, 243-251. [CrossRef]

24. Ju, Y.L.; Lin, Y.; Yang, G.G.; Wu, H.P.; Pan, Y.M. Development of recombinase polymerase amplification assay for rapid detection of Meloidogyne incognita, M. javanica, M. arenaria, and M. Enterolobii. Eur. J. Plant Pathol. 2019, 155, 1155-1163. [CrossRef]

25. Chi, Y.-K.; Zhao, W.; Ye, M.-D.; Ali, F.; Wang, T.; Qi, R.-D. Evaluation of recombinase polymerase amplification assay for detecting Meloidogyne Javanica. Plant Dis. 2020. [CrossRef]

26. Cha, D.J.; Kim, D.S.; Lee, S.K.; Han, H.R. A new on-site detection method for Bursaphelenchus xylophilus in infected pine trees. For. Pathol. 2019, 49, e12503. [CrossRef]

27. Cha, D.; Kim, D.; Choi, W.; Park, S.; Han, H. Point-of-care diagnostic (POCD) method for detecting Bursaphelenchus xylophilus in pinewood using recombinase polymerase amplification (RPA) with the portable optical isothermal device (POID). PLoS ONE 2020, 15, e0227476. [CrossRef]

28. Song, Z.Q.; Yang, X.; Zhang, X.W.; Luan, M.B.; Guo, B.; Liu, C.N.; Pan, J.P.; Mei, S.Y. Rapid and visual detection of Meloidogyne hapla using recombinase polymerase amplification combined with a lateral flow dipstick (RPA-LFD) assay. Plant Dis. 2021, in press. [CrossRef]

29. Peterson, D.J.; Vrain, T.C. Rapid identification of Meloidogyne chitwoodi, M. hapla, and M. fallax using PCR primers to amplify their ribosomal intergenic spacer. Fundam. Appl. Nematol. 1996, 19, 601-605.

30. Petersen, D.J.; Zijlstra, C.; Wishart, J.; Blok, V.; Vrain, T.C. Specific probes efficiently distinguish root-knot nematode species using signature sequences in the ribosomal intergenic spacer. Fundam. Appl. Nematol. 1997, 20, 619-626.

31. Lillis, L.; Siverson, J.; Lee, A.; Cantera, J.; Parker, M.; Piepenburg, O.; Lehman, D.A.; Boyle, D.S. Factors influencing Recombinase polymerase amplification (RPA) assay outcomes at point of care. Mol. Cell. Probes 2016, 30, 74-78. [CrossRef] 